\title{
Gastrointestinal stromal tumors - quantitative detection of the Ki-67, TPX2, TOP2A, and hTERT telomerase subunit mRNA levels to determine proliferation activity and a potential for aggressive biological behavior
}

\author{
A. KALFUSOVA ${ }^{1, *}$, I. HILSKA ${ }^{1}$, L. KRSKOVA ${ }^{1}$, M. KALINOVA ${ }^{1}$, Z. LINKE ${ }^{2}$, R. KODET ${ }^{1}$ \\ ${ }^{1}$ Department of Pathology and Molecular Medicine, Charles University in Prague - $2^{\text {nd }}$ Faculty of Medicine and University Hospital in Motol; \\ ${ }^{2}$ Department of Oncology, Charles University in Prague - $2^{\text {nd }}$ Faculty of Medicine and University Hospital in Motol
}

${ }^{*}$ Correspondence: alena.kalfusova@fnmotol.cz

Received July 14, 2015 / Accepted December 19, 2015

\begin{abstract}
Gastrointestinal stromal tumors (GISTs) have an unpredictable biological potential ranging from benign to malignant. Molecular markers involved in the mechanisms of proliferation and cellular senescence may provide additional information about biological behavior of the tumor. The aim of the present study was to investigate Ki-67, TPX2, TOP2A and hTERT mRNA expression levels in specimens from patients with GISTs to define relationships between proliferation activity and biological potential and progression of the disease. We measured Ki-67, TPX2, TOP2A and hTERT mRNA levels using quantitative realtime reverse transcription PCR (RQ RT PCR). The highest Ki-67, TPX2, TOP2A and hTERT mRNA expression levels were found in the highly proliferative BLs (18 specimens), in comparison with GISTs (137 specimens) and LMSs (9 specimens). Patients with GISTs and adequate information about mitotic activity, tumor size and anatomical site (84 specimens) were divided into two groups - GISTs with benign (29 patients) and with malignant (55 patients) potential. We observed association between higher Ki-67, TPX2 and hTERT mRNA levels and the GISTs with malignant potential. Univariate analysis (57 patients with available follow-up information) of survival (Kaplan Meier curves method) revealed a correlation between higher levels of TPX2, Ki-67 and hTERT markers and shorter event-free survival (EFS) or poorer overall survival (OS). The results demonstrate the importance of quantitative assessment of the proliferation activity in GISTs. Proliferation markers of Ki-67, TPX2, TOP2A and hTERT are suitable markers for detection the proliferation activity and telomerase activity of these tumors. Furthermore, the assessment of TPX2, Ki-67 and hTERT expression levels is appropriate for determination of malignant potential of GISTs.
\end{abstract}

Key words: gastrointestinal stromal tumors (GISTs), proliferation markers, biological behavior, prognosis

Gastrointestinal stromal tumors (GISTs) constitute a distinctive group of mesenchymal tumors of the gastrointestinal tract, based on their morphological and immunohistochemical (IHC) properties, molecular pathogenesis, and responsiveness to target therapy $[1,2]$.

Constitutively activating mutations of KIT and PDGFRA (platelet-derived growth factor receptor alpha) genes are central in the oncogenesis of GISTs, resulting in an increased cell proliferation and enhanced cell survival $[2,3]$.

GISTs represent a heterogenous group of tumors with an unpredictable biological behavior ranging from benign to malignant. Estimation of a potentially aggressive behavior of these neoplasms has found a rationale in contemporary classification schemes but it is still difficult $[1,4,5,6]$.
Assessment of prognosis (risk of relapse or progression of the disease) commonly takes the primary tumor size and mitotic index into consideration. Based on these two variables, Fletcher et al. proposed GIST related risk classification [7]. They categorized GISTs into four risk groups: very low, low, intermediate and high risk

Another important risk factor is the primary site of the tumor. Miettinen et al. [8] extended criteria for evaluating the biological potential of GISTs with regard of the anatomic location.

A final consensus on classification of GISTs into prognostic groups has been worked out by the WHO Classification of Tumours of Soft Tissue and Bone [9]. Though effective and widely used criteria are set, estimation of the biological behavior of 
GISTs is still open to research activities. Information about mechanisms of the tumor proliferation activity and cellular senescence may provide additional information. In the present work we evaluate the proliferation activity and prognosis of GISTs investigating the activity of several molecules. We selected molecular markers which are important regulators of the cell cycle - Ki-67, TPX2, and topoisomerase II alpha (TOP2A), and a marker that is associated with the mechanism of cellular senescence - enzyme telomerase, specifically hTERT telomerase catalytic subunit (hTERT).

$\mathrm{Ki}-67$ is a nuclear proliferation associated antigen expressed in the growth and synthesis phases of the cell cycle (G1, S, G2 and M), but not in the resting phase, G0. This antigen provides information about the proportion of the active cells in the cell cycle [10]. Another molecular marker, TPX2 is a microtubule-associated protein homolog. It plays an important role in mitotic spindle formation, and a segregation of chromosomes during the cell division [11]. TPX2 is expressed exclusively in the proliferating cells in S, G2 and M phases of the cell cycle and its activity accurately corresponds to proliferation activity of cells. TOP2A controls topology of the DNA, chromosome segregation, and cell cycle progression and is used as indicator of the cellular proliferation [12], and moreover is used as molecular target for several anti-cancer chemotherapeutics agents [13]. hTERT is a frequently used marker, which is associated with the mechanism of cellular senescence. The hTERT is an enzymatic human telomerase reverse transcriptase catalytic subunit, one of two components of the enzyme telomerase [14]. Telomerase activity has been observed in $80-90 \%$ of malignant tumors (one of the mechanisms for immortalization of tumor cells is activation of telomerase). This fact suggesting that reactivation of the telomerase plays an important role in the development and/ or progression of neoplastic cells [15].

In this study we have measured the expression of the proliferation markers and hTERT at the mRNA level. Furthermore, we correlated the expression of the above mentioned molecular markers with the proliferation activity and with the biological behavior of GISTs.

\section{Patients and methods}

Patients. The study was performed using the primary tumor specimens diagnosed at the Department of Pathology and Molecular Medicine. All specimens of GISTs and control tissues samples from Burkitt lymphomas (BLs), and leiomyosarcomas (LMSs) (137, 18, and 9 samples, respectively) were processed in a routine way for morphological and IHC examinations at the time of diagnosis.

According to the histopathological criteria assessed by WHO classification [9], we assorted GISTs into two categories: GISTs with benign and malignant potential. In the group of benign GISTs, WHO prognostic groups 1, 2, and 3a (4, 13 , and 12 cases) were included. In the group of malignant GISTs, WHO prognostic categories $3 \mathrm{~b}, 5,6 \mathrm{a}$, and $6 \mathrm{~b}(3,1,5$, and 46 cases) were gathered. To categorize patients within the WHO specific subgroups, we did not have the cohorts of patients large enough for statistical evaluation in individual subgroups. Furthermore, there were no patients with GISTs that would comply with criteria for prognostic group 4 (GISTs with tumor size less than $2 \mathrm{~cm}$ and mitotic rate over 5 mitosis in 50 high power fields, HPF). Of 137 patients with GIST, we were able to obtain complete information about the mitotic activity, anatomic site and tumor size in 84 cases. Of the 84 patients with complete information we analyzed 29 and 55 samples of benign and malignant GISTs, respectively $(34.5 \%$, and $65.5 \%$ ).

Follow-up information was available in 57 patients. A period of follow-up for event free survival time (EFS) and overall survival time (OS) ranged from 1 to 102 months, and from 1 to 124 months, respectively. Median follow-up for EFS and OS was 16 and 41 months. Median age of the patients was 65 years (range, 22 - 91 years). There were 27 females (47\%) and 30 males (53\%). Clinicopathological data of the 57 patients are summarized in Supplementary Table 1.

There were 18 patients (31.6\%) in the group of GISTs with benign potential. In the group of patients with malignant potential there were 39 patients (68.4\%).

For univariate analysis by Kaplan Meier survival we used the Ki-67, TPX2, TOP2A, and hTERT expression levels from the group of 57 patients with the follow-up. Expression levels were analyzed according to two aspects: i.) mean values, and ii.) median values. Patients were categorized as the "high risk" group, if the molecular markers mRNA levels were greater or equal than the mean value, and/or median value. The "low risk" group constituted cases with the mRNA levels that were lower than the mean value, and/or median value. Values of each molecular marker are summarized in Table 1.

Diagnostic tumor tissues were collected and tested after an informed consent given by patients, and with the approval by the Ethical committee.

RNA extraction and cDNA synthesis. RNA was extracted from the formalin fixed and paraffin embedded (FFPE) tissue samples using High Pure RNA Paraffin Kit (Roche Diagnostic, Mannheim, Germany). In case of frozen tissues available, RNA was extracted using Tri-Reagent (Invitrogen Ltd., Carlsbad, CA, USA) according to the manufacturer's instruction.

The complementary DNA (cDNA) was synthesized using reverse transcription (RT) from $10 \mu \mathrm{L}$ isolated RNA in a total

Table 1. Summary of the distribution of Ki-67, TPX2, TOP2A, and hTERT mRNA levels

\begin{tabular}{|c|c|c|c|}
\hline $\begin{array}{l}\text { MOLECULAR } \\
\text { MARKERS }\end{array}$ & $\begin{array}{l}\text { RANGE OF VALUES } \\
\text { (No. of copies) }\end{array}$ & $\begin{array}{c}\text { MEAN } \\
\text { (No. of copies) }\end{array}$ & $\begin{array}{c}\text { MEDIAN } \\
\text { (No. of copies) }\end{array}$ \\
\hline Ki-67 & $0-71.3$ & 4.875 & 0.771 \\
\hline TPX2 & $0-250$ & 23.837 & 7.01 \\
\hline TOP2A & $0-10400$ & 625.483 & 84 \\
\hline hTERT & $0-71.2$ & 2.765 & 0.101 \\
\hline
\end{tabular}


volume of $20 \mu \mathrm{L}$. The processes of RT and cDNA quality control were prepared as described elsewhere [16].

Quantitative Real Time Reverse Transcription PCR (RQ RT PCR)

Plasmid Calibrators. Plasmids of Ki-67, TPX2, TOP2A, and hTERT genes were produced from PCR products of the respective genes that were cloned into the $\mathrm{pCR}^{\circ}-2.1$. TOPO vector. Resulting constructs were transformed into TOP10 competent Escherichia coli cells using $\mathrm{TOPO}^{\circledR} \mathrm{TA}$ cloning Kit (Invitrogen by Life Technologies Corporation, Carlsbad, CA, USA). Cloned plasmids were purified using Jetquick Plasmid Miniprep Spin Kit (Genomed, Löhne, Germany) according to the manufacturer's instructions. ABL plasmid of ABL control gene was produced as described elsewhere [17].

RQ RT PCR . RQ RT PCR analyses were performed using LightCycler 480 detection system (Roche Diagnostic, Mannheim, Germany). The assessment of the expression levels of Ki-67, TPX2, TOP2A, and hTERT catalytic subunit transcript were accomplished using the Universal Probe Library software system for Human (Roche Applied Science, Indianapolis, IN, US). The sequences of the primers and probes are listed in Table 2. Reaction conditions were as follows: reaction mixture comprised FastStart TaqMan Probe Master Mix (Roche Diagnostic, Mannheim, Germany), 500nM of each sense and antisense primers, $100 \mathrm{nM}$ of LNA probe and $1 \mu \mathrm{L} c \mathrm{cNA}$ in a final volume of $20 \mu \mathrm{L}$. The reaction was started with incubation at $50^{\circ} \mathrm{C}$ for 2 minutes, initial denaturation at $95^{\circ} \mathrm{C}$ for 10 minutes, followed by 55 PCR cycles: $95^{\circ} \mathrm{C}$ for 15 seconds and $60^{\circ} \mathrm{C}$ for 1 minute.

Parameters for PCR amplification of $A B L$ transcript: reaction mix contained 2x TaqMan Universal PCR Master Mix (Life Technologies Corporation, Carlsbad, CA, US), 375nM of each sense and antisense primer, 250nM of ABL hydrolysis fluorescent probe and $1 \mu \mathrm{L}$ of cDNA in a final volume of $20 \mu \mathrm{L}$.

Table 2. Sequence of probes and primers

\begin{tabular}{ll}
\hline ABL probe & 5' 6-FAM-CCA TTT TTG GTT TGG GCT TCA CAC \\
& CAT T-TAMRA 3' \\
sense primer & 5' TGG AGA TAA CAC TCT AAG CAT AAC TAA \\
& AGG T 3' \\
antisense primer & 5' GAT GTA GTT GCT TGG GAC CCA 3' \\
Ki67 probe & Universal ProbeLibrary, probe No. 30' \\
sense primer & 5' GAG GTG TGC AGA AAA TCC AAA 3' \\
antisense primer & 5' CTG TCC CTA TGA CTT CTG GTT GT 3' \\
TPX2 probe & Universal ProbeLibrary, probe No. 51 \\
sense primer & 5' ACA TCT GAA CTA CGA AAG CAT CC 3' \\
antisense primer & 5' GGC TTA ACA ATG GTA CAT CCC TTA 3' \\
TOP2A probe & Universal ProbeLibrary, probe No. 76' \\
sense primer & 5' CAA CAT GCC AAT TGA GTG AAA 3' \\
antisense primer & 5' ACT TGG GCC TTA AAC TTC ACC 3' \\
hTERT probe & Universal ProbeLibrary, probe No. 19' \\
sense primer & 5' GCC TTC AAG AGC CAC GTC 3' \\
antisense primer & 5' CCA CGA ACT GTC GCA TGT 3' \\
\hline
\end{tabular}

Roche Applied Science ${ }^{\mathrm{a}}$
The amplification conditions of ABL transcript were derived from those published by Willasch et al. [17]. Detection of Ki-67, TPX2, TOP2A, hTERT and ABL copy numbers was performed according to a standard curve method. Consequent plasmid calibrators of each gene were using for standard curves construction.

Standard curves of the Ki-67, TPX2, TOP2A, hTERT mRNA transcripts and ABL housekeeping gene mRNA transcript were prepared from decimal diluted plasmids. Plasmids were diluted in salmon sperm low-molecular weight DNA (Sigma-Aldrich Corporation, St. Louis, Missouri, US). The concentration range of the ABL housekeeping gene plasmids was from $2.5 \mathrm{E}+07$ to $2.5 \mathrm{E}+01$ copies per $\mu \mathrm{L}$. Standard curves of the mRNA transcript of molecular markers were prepared from a followed concentration range: from $1.45 \mathrm{E}+10$ to $1.45 \mathrm{E}+01$ copies $/ \mu \mathrm{L}$ for Ki-67, from $2.49 \mathrm{E}+09$ to $2.49 \mathrm{E}+01$ copies/ $\mu \mathrm{L}$ for TPX2, from $7.83 \mathrm{E}+09$ to $7.83 \mathrm{E}+04$ copies/ $\mu \mathrm{L}$ for TOP2A, and from $1.8 \mathrm{E}+10$ to $1.8 \mathrm{E}+01$ copies $/ \mu \mathrm{L}$ for hTERT.

RQ RT PCR of Ki-67, TPX2, TOP2A, hTERT and ABL plasmid dilution, non-template control, as well as the quantification of Ki-67, TPX2, TOP2A, hTERT and ABL expression of the respective samples were performed in duplicates.

Normalized expression of Ki-67, TPX2, TOP2A, hTERT transcripts were calculated as a ratio between the expression levels of Ki-67, TPX2, TOP2A, hTERT and ABL housekeeping gene expression levels.

Statistical analysis. For the statistical analysis we used JMP IN 5.1. software (SAS Institute, Cary, NC, US). Kruskal-Wallis nonparametric test was applied to assess differences of the mRNA levels of the molecular markers within GISTs, BLs, and LMSs and benign/malignant potential of GISTs. Univariate analysis of EFS and OS with connection of benign/malignant potential of GISTs and mRNA levels of the molecular markers were performed by the Kaplan-Meier survival method, using the long-rank test. $P$ values less than 0.05 were considered statistically significant.

\section{Results}

Expression levels of the proliferation markers and hTERT in GISTs, BLs, and LMSs. We analyzed a cohort of 137 patients with GISTs, control group of 18 specimens of highly proliferative BLs, and control group of 9 samples of LMSs to determine their proliferation activity. When we compared the expression levels of the proliferation markers in BLs, GISTs, and LMSs, we found the most significant differences in the group of patients with BLs - Ki-67 $(p<0.0001)$, TPX2 $(p<0.0001)$, TOP2A $(p<0.0001)$, and hTERT $(p<0.0001)$ (Figure 1A, 1B, 1C, and 1D). The proliferation activity of Ki67, TPX2, TOP2A, and the activity of hTERT in GISTs and LMSs was significantly lower, than the expression of those molecular markers in BLs. Median values for the mRNA levels of proliferation markers and hTERT of BLs, GISTs, and LMSs are shown in Figure 1. 

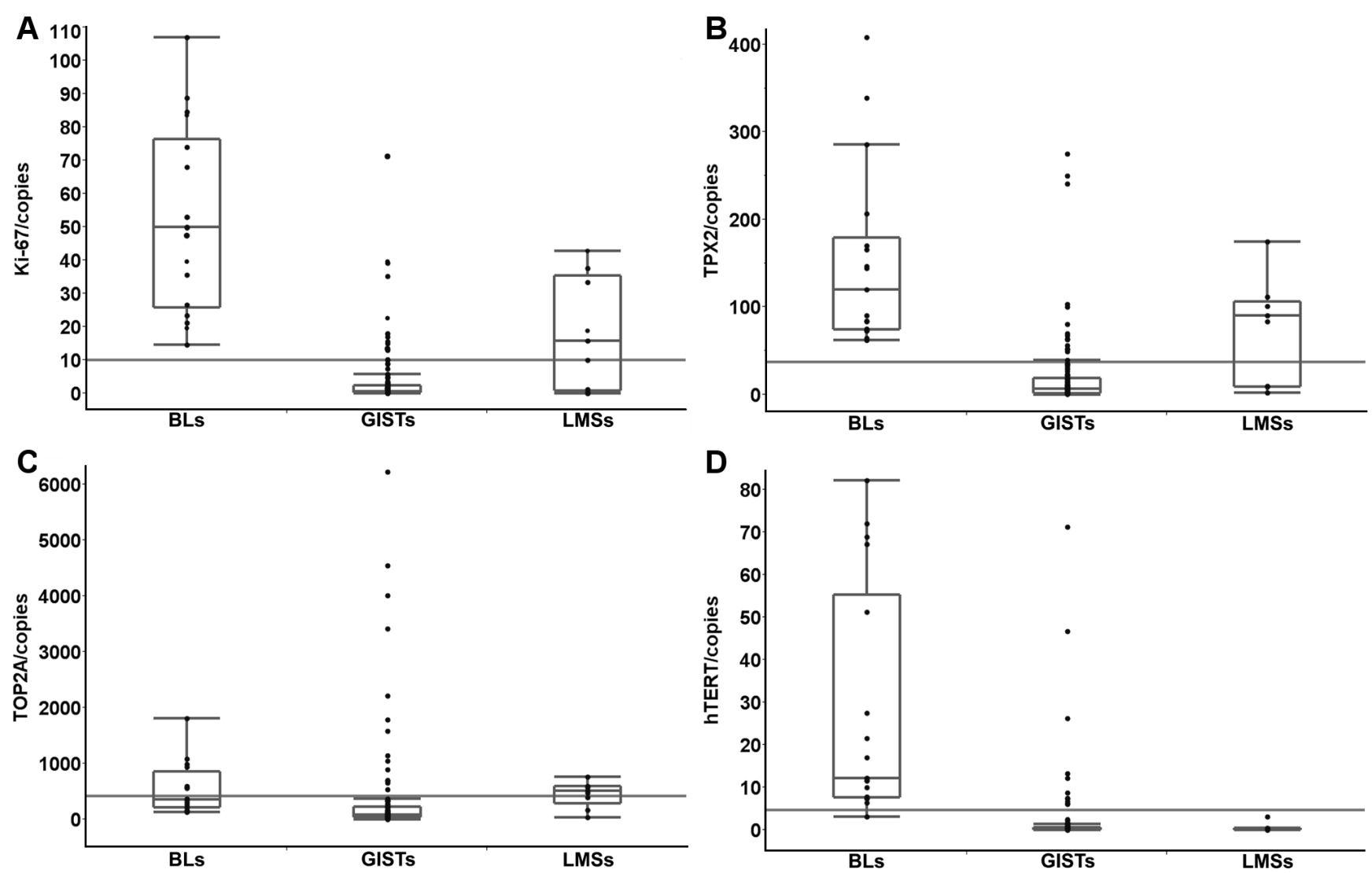

Figure 1. Normalized mRNA levels of molecular markers in GISTs, BLs, and LMSs. Vertical lines of box plot graphs display mRNA levels of Ki-67 (A), TPX2 (B), TOP2A (C), and hTERT (D) in absolute copies. Horizontal lines display individual groups of diseases. The extremities of each box show the 25th-75th percentile. The lines within the boxes represent median values. The bottom and top bars of the whiskers designate the 10th and 90 th percentiles. Outlying values are shown by dots. The result of non-parametric Kruskal-Wallis test was: $p<0.0001$ (for Ki-67), $p<0.0001$ (for TPX2), $p<0.0001$ (for TOP2A), and $p<0.0001$ (for hTERT). The higher mRNA levels of Ki-67, TPX2, TOP2A, and hTERT were significantly associated with BLs.

Abbreviation: BLs - Burkitt lymphomas, GISTs - Gastrointestinal stromal tumors, LMSs - leiomyosarcomas

Median values of the Ki-67, TPX2, TOP2A, and hTERT mRNA levels in BLs, GISTs, and LMSs were follows: 49.95, 0.676, and 15.8 for Ki-67, 120, 6.88, 90 for TPX2, 355.5, 78.5, 517 for TOP2A, and 12.15, 0.0556, 0 for hTERT.

Expression levels of the proliferation markers and hTERT in GISTs with benign and malignant potential. The results revealed that the expression levels of Ki-67, TPX2, and hTERT in the GISTs with malignant potential (prognostic groups $3 \mathrm{~b}, 5,6 \mathrm{a}$, and $6 \mathrm{~b})$ closely correlate $(p<0.0001, p<0.0001$, and $p<0.0001$, respectively). Specimens from prognostic groups $3 \mathrm{~b}, 5,6 \mathrm{a}$, and $6 \mathrm{~b}$ (GISTs with malignant potential) had higher levels of Ki-67, TPX2, and hTERT mRNA than specimens from prognostic groups 1,2 , and 3 a (GISTs with benign potential) (Figure 2A, 2B, and 2D). We did not find any significance in the mRNA levels of TOP2A and benign/malignant potential of GISTs $(p<0.1910)$ (Figure 2C). Median values of the Ki-67, TPX2, TOP2A, and hTERT mRNA levels are summarized in Figure 2. Illustrative comparison of protein Ki-67 expression (IHC method) and comparable mRNA level of Ki-67 (RQ RT PCR) showed Figure 3.

A relationship of the benign / malignant potential of GISTs with EFS and OS. Patients with GISTs and malignant potential manifested a shorter EFS than patients in the group of GISTs with benign potential (log-rank test, $p<0.0040$ ). Patients with GISTs and malignant potential had also a shorter OS than the patients in the group of GISTs with benign potential (log-rank test, $p<0.0263)$. Data not shown.

Relationship of the proliferation markers and hTERT levels with EFS and OS in univariate analysis. Higher levels of Ki-67 and TPX2 mRNA (stratified according to mean values) correlated with shorter EFS and OS, $p<0.0121$ and $p<0.0304$ (for Ki-67 proliferation marker) and $p<0.0003$ and $p<0.0030$ (for TPX2 proliferation marker). If the expression levels of molecular markers were stratified according to median values, shorter EFS was associated with higher TPX2 and hTERT mRNA levels $(p<0.0311$, and $p<0.0106$, respectively). Summarized data are presented in Table 3. Graphical overview of the results of EFS in connection with TPX2 (median values), Ki-67 (mean values) and hTERT (median values) expression levels are shown in Figure 4. 

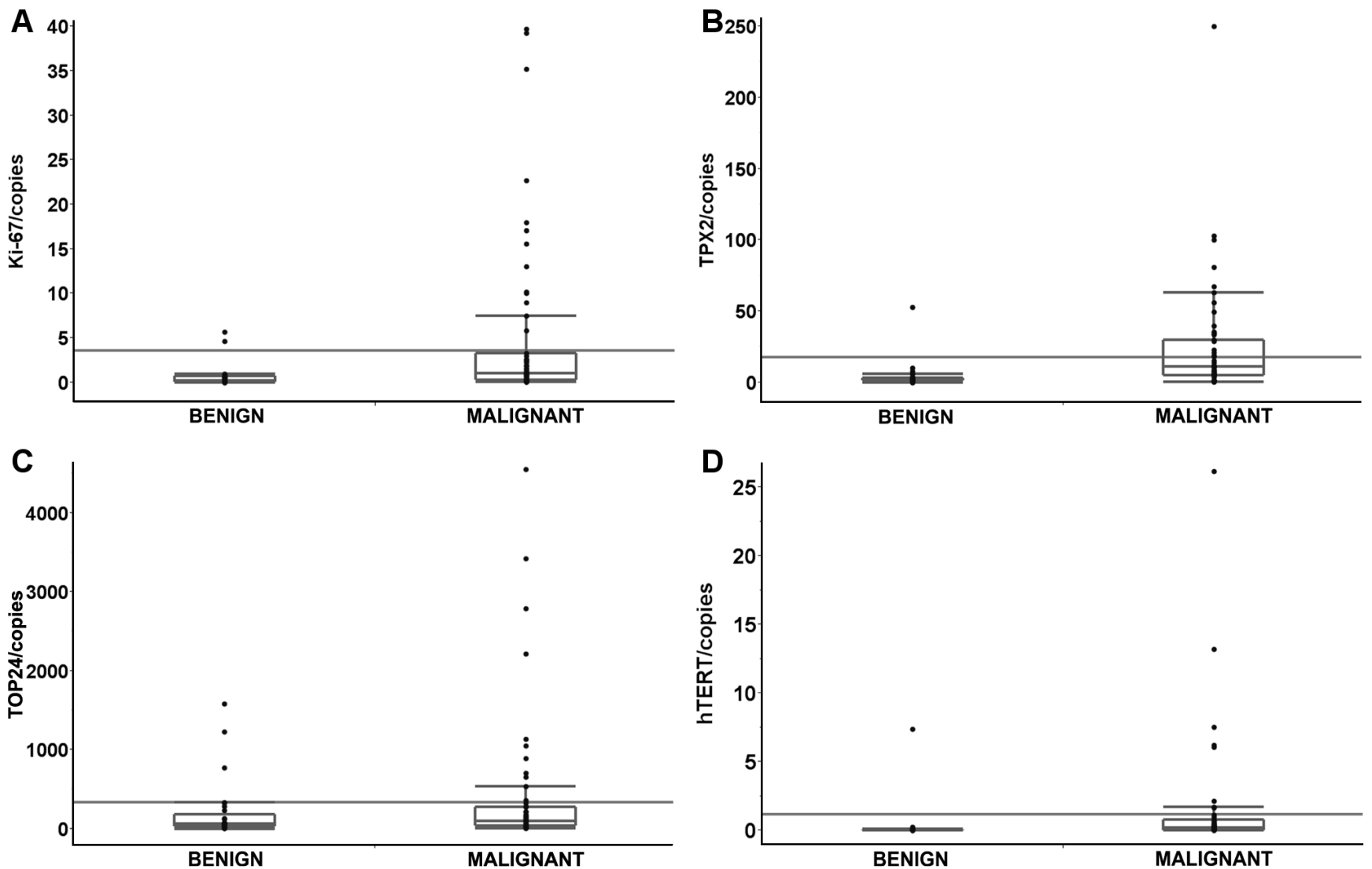

Figure 2. Normalized mRNA levels of molecular markers and group of the GISTs with benign and malignant potential. Vertical lines display Ki-67 (A), TPX2 (B), TOP2A (C), and hTERT (D) mRNA levels in absolute copies. Horizontal lines display groups of GISTs with benign and malignant potential. Expression levels of Ki-67 (A), TPX2 (B), and hTERT (D) molecular markers in GISTs with malignant potential were significantly higher than in GISTs with benign potential $p<0.0001, p<0.0001$, and $p<0.0001$, respectively (non-parametric Kruskal-Wallis test). In TOP2A (C) there was no statistical association between mRNA levels of TOP2A in the groups of GISTs with benign and malignant potential $(p<0.1910)$. Median values of benign and malignant GISTs were as follows: 0.168 and 1.05 for Ki-67, 1.89 and 11.1 for TPX2, 61.2 and 96.7 for TOP2A, and 0 and 0.193 for hTERT.

Table 3. Summary of the parameters of univariate analysis

\begin{tabular}{|c|c|c|c|}
\hline VALUES & $\begin{array}{c}\text { MOLECULAR } \\
\text { MARKER }\end{array}$ & $\begin{array}{l}\text { SURVIVAL } \\
\text { TIME }\end{array}$ & $\begin{array}{c}\text { UNIVARIATE ANALYSIS } \\
\text { P VALUE }\end{array}$ \\
\hline \multirow{8}{*}{ MEAN } & \multirow{2}{*}{ Ki-67 } & EFS & $0.0121^{\mathrm{a}}$ \\
\hline & & OS & $0.0304^{\mathrm{a}}$ \\
\hline & \multirow{2}{*}{ TPX2 } & EFS & $0.0003^{\mathrm{a}}$ \\
\hline & & OS & $0.0030^{\mathrm{a}}$ \\
\hline & \multirow{2}{*}{ TOP2A } & EFS & 0.3435 \\
\hline & & OS & 0.4040 \\
\hline & \multirow{2}{*}{ hTERT } & EFS & 0.1058 \\
\hline & & OS & 0.3455 \\
\hline \multirow{8}{*}{ MEDIAN } & \multirow{2}{*}{ Ki-67 } & EFS & 0.1082 \\
\hline & & OS & 0.4768 \\
\hline & \multirow{2}{*}{ TPX2 } & EFS & $0.0311^{\mathrm{a}}$ \\
\hline & & OS & 0.1080 \\
\hline & \multirow{2}{*}{ TOP2A } & EFS & 0.3065 \\
\hline & & OS & 0.4401 \\
\hline & \multirow{2}{*}{ hTERT } & EFS & $0.0106^{a}$ \\
\hline & & OS & 0.3152 \\
\hline
\end{tabular}

${ }^{\text {a }}$ statistically significant

\section{Discussion}

GISTs are mesenchymal tumors with an unpredictable biological potential ranging from benign to malignant. Many previous studies have proven that the evaluation of proliferative indices is a most useful in distinguishing benign from malignant GISTs $[18,19,20]$. Therefore, the aim of this study was to investigate proliferation and telomerase activity of GISTs to improve our understanding of their proliferation activity and to estimate their malignant potential and prognosis with a greater accuracy than establishing the mitotic rate.

Proliferation marker Ki-67 is a most common and widely used marker for detection of the proliferation activity of tumors using IHC investigations. Data on GISTs based on the IHC results are still controversial. Gelen et al. [19] demonstrated that Ki-67 proliferation index is valuable in predicting a malignant potential of GIST. Correspondingly, Di Vizio et al. [20] published a correlation of Ki-67 overexpression (using methods of IHC analysis) and RFS and OS in GIST patients. 

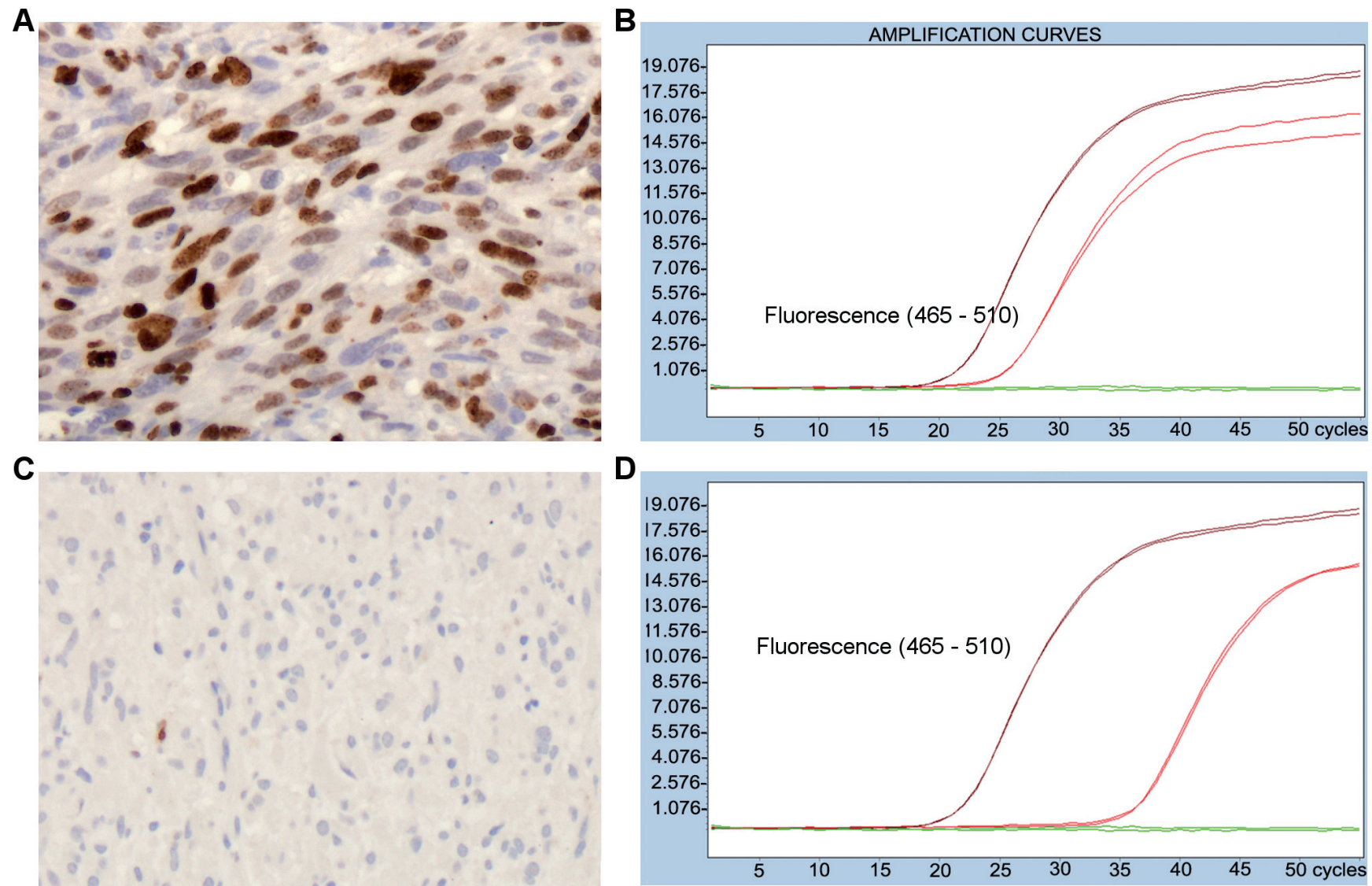

Figure 3. Illustrative picture of protein expression and mRNA levels of Ki-67. Illustrative picture of a high protein Ki-67 expression ( $>50 \%)(\mathrm{A})$, high mRNA level of Ki-67 (1.11E4 absolute copies) (B), low protein Ki-67 expression of (<1\%) (C), and low mRNA level of Ki-67 (2.67E0 absolute copies) (D). Brown lines show amplification curves of plasmid Ki-67 standard samples, red lines display amplification curves of measured samples, and green lines indicate amplification of NTC (no template control).

Other authors investigated, that Ki-67 index $(\leq 5,6-8,>8 \%)$ was an independent prognostic factor for RFS of GIST patients, and moreover that high-risk GIST patients with Ki-67 index $>8 \%$ showed a poorer prognosis even with imatinib adjuvant therapy [21]. However, other investigators did not find any prognostic correlation between Ki-67 proliferation index and mitotic counts, tumor risk groups and the tumor size $[22,23]$. Discrepancy is most probably due to the fact that the IHC method and semiquantitative evaluation of the results is liable to a subjective interpretation of the microscopic findings. In the present study we used data of RQ RT PCR which determines a real amount of the target molecules, expressed as copy numbers of molecules. We confirmed association between Ki-67 mRNA expression levels and proliferation activity of the tumor cells (significantly higher Ki-67 mRNA levels in highly proliferative BLs than in GISTs and in LMSs). We found also a statistical significance of Ki-67 expression levels in the group of GISTs with a malignant potential when compared with benign GISTs. Furthermore, we demonstrated a correlation between overexpression of the Ki-67 mRNA levels (divided according mean values) and both EFS and
OS. At the level of IHC demonstration of Ki-67, Gelen et al. determined significant differences of Ki-67 proliferation index between three groups of GISTs (benign, borderline and malignant) [19]. Group of GISTs with uncertain malignant potential (a borderline group) has not been investigated in this study. Molecular analyses of mutation state of KIT and PDGFRA genes and mRNA levels of proliferation markers were primarily carried out in patients with malignant potential (size over $5 \mathrm{~cm}$, high mitotic rate), and specifically in metastatic, inoperable or recurrent tumors. The reason for focusing preferably on patients with unfavorable GISTs lays in therapy targeting potentially responsive GISTs by tyrosin kinase inhibitors. Patients categorized in the WHO prognostic group 4 are relatively uncommon $[8,9]$, and we had no such a patient for statistical analysis. Furthermore, the aim of the study was to ascertain whether we may separate clear polarities, e.g. benign and malignant lesions by the tools utilized in this study.

Beside establishing the proliferation activity of the tumor by the Ki-67 index, some authors focused on the expression of TOP2A activity. Wong et al. [24] observed that TOP2A expres- 
sion correlated with more aggressive hepatocellular carcinoma (HCC) phenotype and patient responsiveness to doxorubicinbased therapy. De Resende et al. [25] reported that patients with higher expression of TOP2A presented shorter BRFS (biochemical recurrence-free survival) in prostate cancer. Our observation with TOP2A expression also revealed a relation between high tumor proliferation activity and higher TOP2A
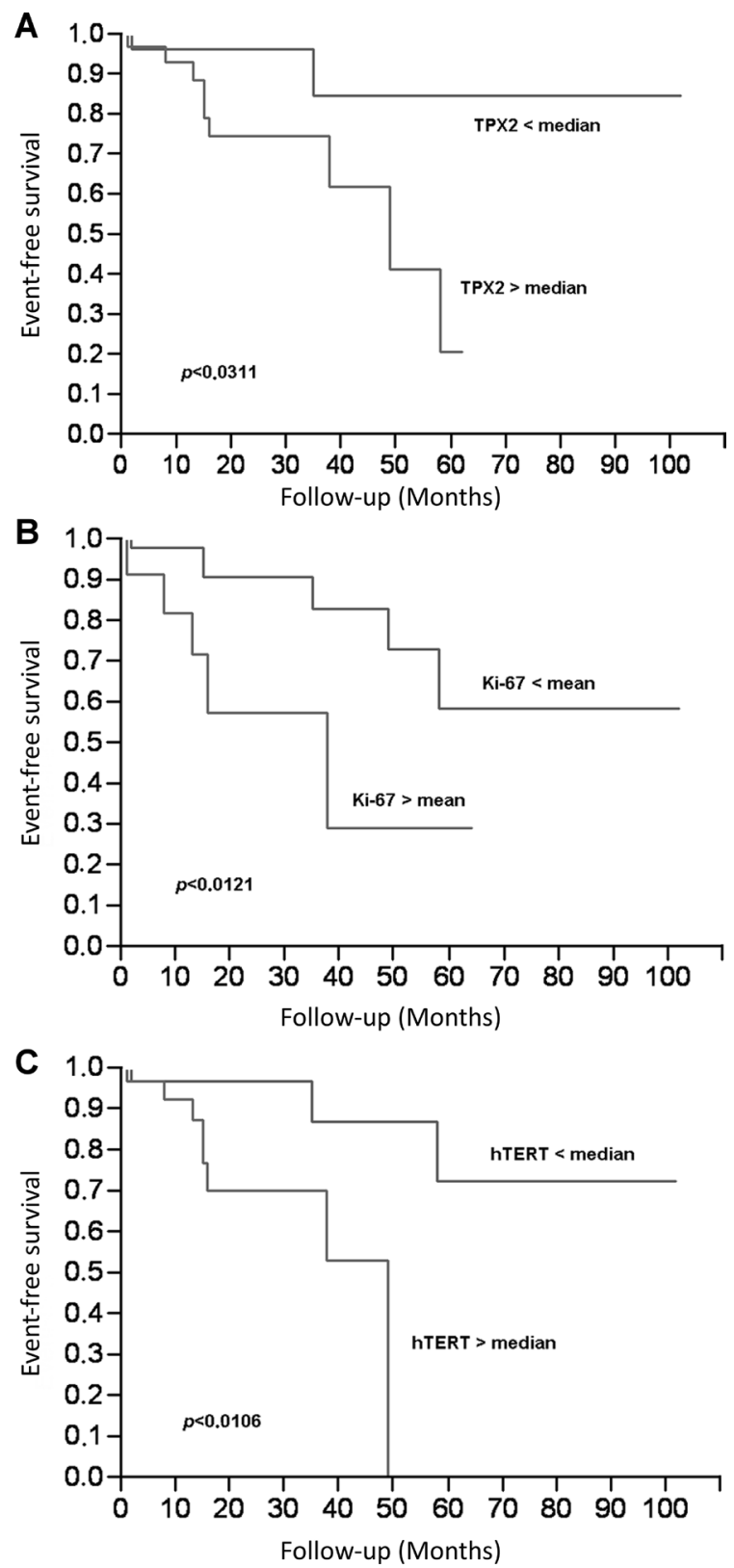

Figure 4. Kaplan Meier survival analysis of the EFS and mRNA levels of TPX2, Ki-67, and hTERT. EFS rates of the patients with GISTs distributed with respect of median values of the TPX2 mRNA levels (A), EFS rates in the connection of Ki-67 mRNA levels distributed according mean values (B), EFS rates in the connection of hTERT mRNA levels distributed according median values $(C)$.
mRNA levels. In contrast with these findings we did not find a statistical significance of TOP2A mRNA levels in connection with benign / malignant potential of GISTs. Likewise, we did not observe association between higher TOP2A levels and the outcome of the patients with GISTs in EFS and OS. The results obtained in our study may be explained at least partially by time lapse studies of TOP2A through cell cycle by Stacey et al. [26]. These studies indicate that the expression of TOP2A in tumor cells is less dependent on the proliferation state of malignant cells. Authors further reported that the cells which remain viable but are temporarily removed from the active cell cycle were able to become dominant and produce high levels of TOP2A. The explanation may rest in the fact that slowly growing cells do not actively proliferate. Therefore, the differences of the TOP2A mRNA levels in the GISTs with benign and malignant potential (probably comprise a majority of slowly growing cells) are not so significant.

Reactivation of telomerase is believed to play a role in tumor cell immortalization. Wang et al. [27] reported that detection of telomerase activity, apoptosis and control genes (P53 and BCL2) in GISTs will be helpful in the evaluation of the prognosis, and discrimination between malignant and benign GISTs. Similarly, Tominaga et al. [28] reported a strong relationship between detection of the telomerase activity and expression levels of hTERT in neoplastic and non-neoplastic esophageal lesions. In our study, we measured hTERT mRNA levels by means of RQ RT PCT technique. A similar approach was published by Capkova et al. [29] in bronchial mucosa of heavy smokers. Expression of the hTERT in the tumors of the gastrointestinal tract (cholangiocarcinoma, HCC and GISTs), and in non-neoplastic tissues was determined by others [30]. These authors found expression of hTERT mRNA in carcinomas but not in GISTs and non-neoplastic tissues. In contrast with their results, we detected expression of hTERT mRNA levels not only within highly proliferating tumors such as BLs, but also in GISTs and LMSs. More importantly, we demonstrated association of the hTERT mRNA level and GISTs with malignant potential. Same results were reported by Gunther et al. [31]. They compared extra-gastrointestinal myogenic or neurogenic sarcomas and GISTs. According to their study, malignant GISTs expressed telomerase at a significantly higher level than LMSs and malignant peripheral nerve sheath tumors.

TPX2 plays a pivotal role in the cell cycle promotion and mitotic cell division. TPX2 is expressed exclusively in the proliferating cells in S, G2 and M phases of the cell cycle and its activity corresponds to proliferation activity of cells [32]. Because of exclusive expression of TPX2 in proliferating cells, many studies indicate that determination of TPX2 expression is more suitable to determine the proliferation than $\mathrm{Ki}-67$ in breast carcinoma [33], mantle cell lymphoma (MCL) [34, 35], neuroblastoma [36], colon cancer [37] and squamous cell carcinoma of the larynx [38]. Also, the estimation of TPX2 expression is a helpful and most precise prognostic indicator in various other diseases $[11,39,40,41]$. In the 
present study, the TPX2 and also Ki-67 mRNA levels were associated not only with the proliferation activity of GISTs, but also with their biological potential (progression and unfavorable prognosis). Our observation suggests, that a higher TPX2 and Ki-67 mRNA expression levels was associated with highly proliferative tumors. Furthermore, a higher TPX2 and Ki-67 mRNA expression levels was significantly associated with a malignant clinical behavior of the GISTs. We also investigated that the TPX2 and Ki-67 mRNA levels (divided according mean values) were significantly associated with a shorter EFS and OS in patients with GISTs. On the other hand, only TPX2 and hTERT mRNA levels (not Ki-67 mRNA levels) divided according median values were associated with shorter EFS.

In conclusion, normalized mRNA expression levels of molecular markers Ki-67, TPX2, TOP2A, and hTERT are suitable markers for detection of the proliferation activity and telomerase activity of the GISTs. Our results suggest that determination of the expression status of Ki-67, TPX2 and hTERT are helpful for supporting the discrimination of the benign / malignant potential of GISTs. We demonstrated that combination of the measurement of Ki-67, TPX2 and hTERT expression by means of RQ RT PCR appears to be a suitable tool for diagnostic and prognostic purposes of GISTs. The assessment of Ki-67 and TPX2 and hTERT mRNA expressions could be a candidate for an improvement of GISTs prognostic estimation.

We confirmed that mRNA expression of Ki-67, TPX2, and hTERT molecular markers corresponded with morphologically defined groups of benign and malignant GISTs. In a further study we will focus on a group of GIST with uncertain malignant potential.

Acknowledgements: This study was supported by the project (Ministry of Health, Czech Republic) for conceptual development of research organization 00064203 (University Hospital Motol, Czech Republic), and GAUK registration number 198213 (internal number 2120 152).

\section{References}

[1] MiETTINEN M, SARLOMO-RIKALA M, LASOTA J. Gastrointestinal stromal tumors: recent advances in understanding of their biology. Hum Pathol 1999; 30: 1213-1220. http://dx.doi.org/10.1016/S0046-8177(99)90040-0

[2] JOENSUU H. Current perspectives on the epidemiology of gastrointestinal stromal tumours. EJC Supplements 2006; 4: 4-9. http://dx.doi.org/10.1016/S1359-6349(06)80468-4

[3] LASOTA J, CORLESS CL, HEINRICH MC, DEBIECRYCHTER M, SCIOT R et al. Clinicopathologic profile of gastrointestinal stromal tumors (GISTs) with primary KIT exon 13 or exon 17 mutations: a multicenter study on 54 cases. Mod Pathol 2008; 21: 476-484. http://dx.doi.org/10.1038/ modpathol.2008.2

[4] GUPTA P, TEWARI M, SHUKLA HS. Gastrointestinal stromal tumor. Surg Oncol 2008; 17: 129-138. http://dx.doi. org/10.1016/j.suronc.2007.12.002
[5] SABAH M, CUMMINS R, LEADER M, KAY E. Altered expression of cell cycle regulatory proteins in gastrointestinal stromal tumors: markers with potential prognostic implications. Hum Pathol 2006; 37: 648-655. http://dx.doi. org/10.1016/j.humpath.2006.01.023

[6] SAMELIS GF, EKMEKTZOGLOU KA, ZOGRAFOS GC. Gastrointestinal stromal tumours: clinical overview, surgery and recent advances in imatinib mesylate therapy. Eur J Surg Oncol 2007; 33: 942-950. http://dx.doi.org/10.1016/j. ejso.2006.11.025

[7] FLETCHER CD, BERMAN JJ, CORLESS C, GORSTEIN F, LASOTA J et al. Diagnosis of gastrointestinal stromal tumors: A consensus approach. Hum Pathol 2002; 33: 459-465. http:// dx.doi.org/10.1053/hupa.2002.123545

[8] MIETTINEN M, LASOTA J. Gastrointestinal stromal tumors: review on morphology, molecular pathology, prognosis, and differential diagnosis. Arch Pathol Lab Med 2006; 130: 1466-1478.

[9] FLETCHER C.D.M. et al. WHO Classification of Tumours of Soft Tissue and Bone. IARC: Lyon 2013

[10] NEVES LR, OSHIMA CT, ARTIGIANI-NETO R, YANAGUIBASHI G, LOURENCO LG et al. Ki67 and p53 in gastrointestinal stromal tumors-GIST. Arq Gastroenterol 2009; 46: 116-120. http://dx.doi.org/10.1590/S000428032009000200008

[11] WARNER SL, STEPHENS BJ, NWOKENKWO S, HOSTETTER G, SUGENG A et al. Validation of TPX2 as a potential therapeutic target in pancreatic cancer cells. Clin Cancer Res 2009; 15: 6519-6528. http://dx.doi.org/10.1158/1078-0432. CCR-09-0077

[12] TRETIAKOVA M, TURKYILMAZ M, GRUSHKO T, KOCHERGINSKY M, RUBIN C et al. Topoisomerase IIalpha in Wilms' tumour: gene alteration and immunoexpresion. J Clin Pathol 2006; 59: 1272-1277. http://dx.doi.org/10.1136/ jcp. 2005.031963

[13] SIMON R, ATEFY R, WAGNER U, FORSTER T, FIJAN A et al. HER-2 and TOP2A coamplification in urinary bladder cancer. Int J Cancer 2003; 107: 764-772. http://dx.doi. org/10.1002/ijc.11477

[14] KEITH WN, JEFFRY EVANS TR, GLASSPOOL RM. Telomerase and cancer: time to move from a promising target to clinical reality. J Pathol 2001; 195: 404-414. http://dx.doi. org/10.1002/path.1001

[15] SAKURAI S, FUKAYAMA M, KAIZAKI Y, SAITO K, KANAZAWA $\mathrm{K}$ et al. Telomerase activity in gastrointestinal stromal tumors. Cancer 1998; 83: 2060-2066. http://dx.doi. org/10.1002/(SICI) 1097-0142(19981115)83:10<2060::AIDCNCR3>3.0.CO;2-\#

[16] BRIZOVA H., KALINOVA M, KRSKOVA L, MARHALOVA M, KODET R. Quantitative measurement of cyclin D1 mRNA, a potent diagnostic tool to separate mantle cell lymphoma from other B-cell lymphoproliferative disorders. Diagn Mol Pathol 2008; 17: 39-50 http://dx.doi.org/10.1097/ pdm.0b013e318146959a

[17] WILLASCH AM, GRUHN B, COLIVA T, KALINOVA M, SCHNEIDER G et al., Standardization of WT1 mRNA quantitation for minimal residual disease monitoring in childhood 
AML and implications of WT1 gene mutations: a European multicenter study. Leukemia 2009; 23: 1472-1479. http:// dx.doi.org/10.1038/leu.2009.51

[18] NAKAMURA N, YAMAMOTO H, YAO T, ODA Y, NISHIYAMA K et al. Prognostic significance of expressions of cell-cycle regulatory proteins in gastrointestinal stromal tumor and the relevance of the risk grade. Hum Pathol 2005; 36: 828-837. http://dx.doi.org/10.1016/j.humpath.2005.03.012

[19] GELEN MT, ELPEK GO, AKSOY NH, OGUS M, SULEYMANLAR I et al. p27 expression and proliferation in gastrointestinal stromal tumors. Turk J Gastroenterol 2003; 14: $132-137$.

[20] Di VIZIO D, DEMICHELIS F, SIMONETTI S, PETTINATO G, TERRACCIANO L et al. Skp2 expression is associated with high risk and elevated Ki67 expression in gastrointestinal stromal tumours. BMC Cancer 2008; 8: 134. http://dx.doi. org/10.1186/1471-2407-8-134

[21] ZHAO WY, XU J, WANG M, ZHANG ZZ, TU L et al. Prognostic value of Ki67 index in gastrointestinal stromal tumors. Int J Clin Exp Pathol 2014; 7: 2298-2304.

[22] GUMURDULU D, ERDOGAN S, KAYASELCUK F, SEYDAOGLU G, PARSAK CK et al. Expression of COX-2, PCNA, Ki-67 and p53 in gastrointestinal stromal tumors and its relationship with histopathological parameters. World J Gastroenterol 2007; 13: 426-431. http://dx.doi.org/10.3748/ wig.v13.i3.426

[23] KWON MJ, NAM ES, CHO SJ, PARK HR, SHIN HS et al. The expressions of E2F1 and p53 in gastrointestinal stromal tumors and their prognostic significance. Korean J Pathol 2009; 43: 212-220. http://dx.doi.org/10.4132/ KoreanJPathol.2009.43.3.212

[24] WONG N, YEO W, WONG WL, WONG NL, CHAN KY et al. TOP2A overexpression in hepatocellular carcinoma correlates with early age onset, shorter patients survival and chemoresistance. Int J Cancer 2009; 124: 644-652. http:// dx.doi.org/10.1002/ijc.23968

[25] de RESENDE MF, VIEIRA S, CHINEN LT, CHIAPPELLI F, da FONSECA FP et al. Prognostication of prostate cancer based on TOP2A protein and gene assessment: TOP2A in prostate cancer. J Transl Med 2013; 11: 36. http://dx.doi. org/10.1186/1479-5876-11-36

[26] STACEY DW, HITOMI M, CHEN G. Influence of cell cycle and oncogene activity upon topoisomerase IIalpha expression and drug toxicity. Mol Cell Biol 2000; 20: 9127-9137. http:// dx.doi.org/10.1128/MCB.20.24.9127-9137.2000

[27] WANG Q, KOU YW. Study of the expressions of p53 and bcl-2 genes, the telomerase activity and apoptosis in GIST patients. World J Gastroenterol 2007; 13: 2626-2628. http:// dx.doi.org/10.3748/wig.v13.i18.2626

[28] TOMINAGA T, KASHIMURA H, SUZUKI K, NAKAHARA A, TANAKA $\mathrm{N}$ et al. Telomerase activity and expression of human telomerase catalytic subunit gene in esophageal tissues. J Gastroenterol 2002; 37: 418-427. http://dx.doi.org/10.1007/ $\underline{\text { s005350200061 }}$

[29] CAPKOVA L, KALINOVA M, KRSKOVA L, KODETOVA D, PETRIK F et al. Loss of heterozygosity and human telomerase reverse transcriptase (hTERT) expression in bronchial mucosa of heavy smokers. Cancer 2007; 109: 2299-2307. http://dx.doi. org/10.1002/cncr.22683

[30] Udomchaiprasertkul W, Narong S, Kongsema M, Leelawat K. Detection of hTERT mRNA in gastrointestinal tract cancer specimens. Southeast Asian J Trop Med Public Health 2008; 39: 324-327.

[31] Gunther T, Schneider-Stock R, Hackel C, Pross M, SCHULZ HU et al. Telomerase activity and expression of hTRT and hTR in gastrointestinal stromal tumors in comparison with extragastrointestinal sarcomas. Clin Cancer Res 2000; 6: 1811-1818.

[32] HEIDEBRECHT HJ, BUCK F, STEINMANN J, SPRENGER R, WACKER HH et al. p100: A novel proliferation-associated nuclear protein specifically restricted to cell cycle phases $\mathrm{S}$, G2, and M. Blood 1997; 90: 226-233.

[33] RUDOLPH P, ALM P, HEIDEBRECHT HJ, BOLTE H, RATJEN V et al. Immunologic proliferation marker Ki-S2 as prognostic indicator for lymph node-negative breast cancer. J Natl Cancer Inst 1999; 91: 271-278. http://dx.doi.org/10.1093/ jnci/91.3.271

[34] BRIZOVA H, KALINOVA M, KRSKOVA L, MRHALOVA M, KODET R. A novel quantitative PCR of proliferation markers (Ki-67, topoisomerase IIalpha, and TPX2): an immunohistochemical correlation, testing, and optimizing for mantle cell lymphoma. Virchows Arch 2010; 456: 671-679. http://dx.doi. org/10.1007/s00428-010-0922-8

[35] SCHRADER C, JANSSEN D, MEUSERS P, BRITTINGER G, SIEBMANN JU et al. Repp86: a new prognostic marker in mantle cell lymphoma. Eur J Haematol 2005; 75: 498-504. http://dx.doi.org/10.1111/j.1600-0609.2005.00540.x

[36] KRAMS M, HEIDEBRECHT HJ, HERO B, BERTHOLD F, HARMS D et al. Repp86 expression and outcome in patients with neuroblastoma. J Clin Oncol 2003; 21: 1810-1819. http:// dx.doi.org/10.1200/JCO.2003.05.076

[37] WEI P, ZHANG N, XU Y, LI X, SHI D et al. TPX2 is a novel prognostic marker for the growth and metastasis of colon cancer. J Transl Med 2013; 11: 313. http://dx.doi. org/10.1186/1479-5876-11-313

[38] CORDES C, MUNZEL AK, GOROGH T, LEUSCHNER I, AMBROSCH P et al. Prognostic relevance of the proliferation marker REPP86 for laryngeal cancer. Anticancer Res 2010; 30: 3541-3547.

[39] MA Y, LIN D, SUN W, XIAO T, YUAN J et al. Expression of targeting protein for xklp2 associated with both malignant transformation of respiratory epithelium and progression of squamous cell lung cancer. Clin Cancer Res 2006; 12: 1121-1127. http://dx.doi.org/10.1158/1078-0432.CCR-05-1766

[40] SHIGEISHI H, OHTA K, HIRAOKA M, FUJIMOTO S, MINAMI $\mathrm{M}$ et al. Expression of TPX2 in salivary gland carcinomas. Oncol Rep 2009; 21: 341-344.

[41] LI B, QI XQ, CHEN X, HUANG X, LIU GY et al. Expression of targeting protein for Xenopus kinesin-like protein 2 is associated with progression of human malignant astrocytoma. Brain Res 2010; 1352: 200-207. http://dx.doi.org/10.1016/j. brainres.2010.06.060 